\title{
Analysis and Development of Urdu POS Tagged Corpus
}

\author{
Ahmed Muaz \\ Center for Research in Urdu \\ Language Processing \\ NUCES, Pakistan \\ ahmed.muaz@nu.edu.pk
}

\author{
Aasim Ali \\ Center for Research in Urdu \\ Language Processing, \\ NUCES, Pakistan \\ aasim.ali@nu.edu.pk
}

\author{
Sarmad Hussain \\ Center for Research in Urdu \\ Language Processing \\ NUCES, Pakistan \\ sarmad.hussain@nu.edu.pk
}

\begin{abstract}
In this paper, two corpora of Urdu (with $110 \mathrm{~K}$ and $120 \mathrm{~K}$ words) tagged with different POS tagsets are used to train TnT and Tree taggers. Error analysis of both taggers is done to identify frequent confusions in tagging. Based on the analysis of tagging, and syntactic structure of Urdu, a more refined tagset is derived. The existing tagged corpora are tagged with the new tagset to develop a single corpus of $230 \mathrm{~K}$ words and the TnT tagger is retrained. The results show improvement in tagging accuracy for individual corpora to $94.2 \%$ and also for the merged corpus to $91 \%$. Implications of these results are discussed.
\end{abstract}

\section{Introduction}

There is increasing amount of work on computational modeling of Urdu language. As various groups work on the language, diversity in analysis is also developed. In this context, there has been some work on Urdu part of speech (POS) tagging, which has caused multiple tagsets to appear. Thus, there is also need to converge these efforts.

Current work compares the existing tagsets of Urdu being used for tagging corpora in an attempt to look at the differences, and understand the reasons for the variation. The work then undertakes experiments to develop a common tagset, which is syntactically and computationally coherent. The aim is to make a robust tagset and then to port the differently tagged Urdu corpora onto the same tagset. As Urdu already has very few annotated corpora, this will help consolidating them for better modeling.

The next sections present the existing tagsets and accuracies of the POS taggers reported using them. Sections 4 and 5 present baseline experiment and the methodology used for the analysis for updating the tagset. Section 6 describes the proposed tagset. Section 7 reports experiments comparing the new tagset with ex- isting ones. Section 8 discusses the results achieved and future directions.

\section{Relevant Resources of Urdu}

\section{$2.1 \quad$ Urdu Corpora}

Several annotated corpora have been built during last few years to facilitate computational processing for Urdu language. The initial work was undertaken through EMILLE project to build multi-lingual corpora for South Asian languages (McEnery et al., 2000). They released 200,000 words parallel corpus of English, Urdu, Bengali, Gujarati, Hindi and Punjabi. In addition, there are 1,640,000 words of Urdu text in this corpus. These text collections are also annotated with part of speech tags (Hardie 2003).

Center for Research in Urdu Language Processing (CRULP ${ }^{1}$ ) gathered 18 million words corpus in order to build a lexicon. It has cleaned text from news websites from multiple domains (Ijaz et.al. 2007). Following this work, a syntactic tagset was developed based on work by existing grammarians and a corpus of 110,000 words was manually tagged. This annotated corpus is available through the center (Sajjad 2007, Hussain 2008).

Recently an English-Urdu parallel corpus has also been developed by CRULP, by translating the first 140,000 words of PENN Treebank corpus. In addition, a tagset has also been designed following the PENN Treebank guidelines. These words have been tagged manually with this new tagset. This collection is also available from CRULP, and the tagset is still unpublished.

\subsection{Urdu Part of Speech tagsets}

Hardie (2003) developed the first POS tagset for Urdu using EAGLES guidelines for computational processing. The tagset contains 282 morpho-syntactic tags, differentiating on the basis of number, gender and other morphological details

\footnotetext{
${ }^{1}$ www.crulp.org
} 
in addition to the syntactic categories. Punctuation marks are tagged as they are, and not included in 282 tags. The tags include the gender and number agreement, in addition to syntactic information.

The complications of Urdu tagset design are also discussed. One of these complexities is word segmentation issue of the language. Suffixes in Urdu are written with an orthographic space. Words are separated on the basis of space and so suffixes are treated same as lexical words. Hence it is hard to assign accurate tag for an automatic tagger. Although the tagset is designed considering details, but due to larger number of tags it is hard to get a high accuracy with a small sized corpus. Due to its morphological dependence and its large size, this tagset is not considered in our analysis.

Two much smaller tagsets are considered for this work. They are compared in detail in Section 6 . The first tagset, containing 42 tags, is designed by Sajjad (2007), based on the work of Urdu grammarians (e.g. Schmidt 1999, Haq 1987, Javed 1981, Platts 1909) and computational work by Hardie (2003). The main features of the tagset include multiple pronouns ( $\mathrm{PP}, \mathrm{KP}$, AKP, AP, RP, REP, G, and GR) and demonstratives (PD, KD, $\mathrm{AD}$, and $\mathrm{RD}$ ). It has only one tag for all forms of verbs (VB), except for auxiliaries to show aspect (AA) and tense (TA) information about the verb. All noun types are assigned single tag (NN) except for Proper Nouns (PN). It also has a special tag NEG to mark any occurrence negation words (نهيي "not” and ن "no" or "neither") regardless of context. It also has a tag SE to mark every occurrence of « ("from") without considering the context. Another example of such a context-free lexical tag is WALA to mark every occurrence (including all the inflections) of the word والا This tagset is referred to as $\mathrm{T} 1$ subsequently in this paper.

Recently Sajjad and Schmid (2009) used the tagged data of 107,514 words and carried out an experiment for tagger comparison. A total of 100,000 words are used as training set and rest as test data. Four taggers (TnT, Tree, RF and SVM) are trained using training corpus and then tested accordingly. Reported results of this work show that SVM tagger is the most accurate, showing $94.15 \%$ correct prediction of tags. Remaining three taggers have accuracies of $93.02 \%$ (Tree tagger), 93.28\% (RF tagger) and 93.40\% (TnT tagger).
Another tagset has recently been developed as a part of a project to develop EnglishUrdu parallel corpus at CRULP, following the Penn Treebank guidelines (Santorini 1990). It contains 46 tags, with fewer grades of pronouns (PR, PRP\$, PRRF, PRRFP\$, and PRRL) and demonstratives (DM and DMRL), as compared to T1. It has several tags for verbs on the basis of their forms and semantics (VB, VBI, VBL, VBLI, and VBT) in addition to the tags for auxiliaries showing aspect (AUXA) and tense (AUXT). The NN tag is assigned for both singular and plural nouns and includes adverbial kaf pronoun, kaf pronoun, and adverbial pronoun categories of T1. Yet, it has several other grades of common nouns (NNC, NNCR, NNCM). It also has two shades of Proper Nouns (NNP, NNPC), which are helpful in identifying phrase boundary of compound proper nouns. It also has a tag WALA that is assigned to every occurrence (and inflection) of word والا (wala). However, marking of token $\Longleftarrow$ ("from") is context dependent: either it is CM when marking case or it is RBRP when occurring as an adverbial particle. This tagset is referred to as T2 subsequently in this paper.

\section{Tools and Resource Selection}

The decision of selecting the tagger, the tagset, and the data is the starting point for the task of POS tagging. This section gives details of the taggers chosen and the corpora used for the experiments conducted.

\subsection{Selection of taggers}

There are a number of existing taggers available for tagging. Two POS taggers are used in the initial step of this work to compare the initial tagging accuracies.

One of the selected taggers is Trigramand-Tag (TnT). It is a trigram based HMM tagger in which two preceding tags are used to find the transition probability of a tag. Brants (2000) tested PENN Treebank (English) and NEGRA (German) corpora and reported 96-97\% accuracy of the tagger.

Schmid (1994) proposed probabilistic POS tagger that uses decision trees to store the transition probabilities. The trained decision tree is used for identification of highest probable tags. Schmid reported an accuracy of $95-96 \%$ on PENN Treebank for this tagger. 
Both taggers give good accuracy for Urdu tagging, as reported by Sajjad and Schmid (2009).

\subsection{Data Used for Experimentation}

Corpora annotated with the different tagsets are acquired from CRULP. The corpus originally tagged with T1 tagset is referred to as C1 (news from non-business domain) and the corpus initially annotated with T2 tagset is referred to as C2 (news from business domain), subsequently in the current work. Both C1 and C2 are taken and cleaned. The data is re-counted and approximately 100,000 words are separated for training and rest are kept for testing. The details of data are given in Tables 1 and 2 below.

Table 1. Number of tokens in Urdu corpora

\begin{tabular}{|c|c|c|}
\hline Tokens & C1 & C2 \\
\hline Training & 101,428 & 102,454 \\
\hline Testing & 8,670 & 21,181 \\
\hline Total & 110,098 & 123,635 \\
\hline
\end{tabular}

Table 2. Number of sentences in Urdu corpora

\begin{tabular}{|c|c|c|}
\hline Sentences & C1 & C2 \\
\hline Training & 4,584 & 3,509 \\
\hline Testing & 404 & 755 \\
\hline Total & 4,988 & 4,264 \\
\hline
\end{tabular}

\section{Baseline Estimation}

The comparison is initiated with training of existing tagsets on their respective annotated data (T1 on C1 and T2 on C2). Both corpora are tested on TnT and Tree Tagger to obtain the confusion matrices for errors. These confusion matrices are used to analyze misclassification of tags. TnT tagger shows that overall accuracy of using T1 with C1 is $93.01 \%$ and is significantly better than using $\mathrm{T} 2$ with $\mathrm{C} 2$, which gives 88.13\% accuracy. Tree tagger is also trained on the corpora. The overall accuracy of $\mathrm{T} 1$ on $\mathrm{C} 1$ (93.37\%) is better than that of $\mathrm{T} 2$ on $\mathrm{C} 2$ (90.49\%). The results are shown in Table 3.

Table 3. Results of both tagsets on their respective corpora with $\mathrm{TnT}$ and Tree taggers

\begin{tabular}{|c|c|c|}
\hline & T1 on C1 & T2 on C2 \\
\hline TnT Tagger & $93.01 \%$ & $88.13 \%$ \\
\hline Tree Tagger & $93.37 \%$ & $90.49 \%$ \\
\hline
\end{tabular}

The accuracies reported (for T1 on C1) by Sajjad and Schmid (2009) are comparable to these accuracies. They have reported $93.40 \%$ for TnT Tagger and 93.02\% for Tree Tagger.

Further experimentation is performed only using TnT tagger.

\section{Methodology}

The current work aims to build a larger corpus of around 230,000 manually tagged words for Urdu by combining $\mathrm{C} 1$ and $\mathrm{C} 2$. These collections are initially annotated with two different tagsets (T1 and T2 respectively, and as described above). For this unification, it was necessary to indentify the differences in the tagsets on which these corpora are annotated, analyzed the differences and then port them to unified tagset.

The work starts with the baseline estimation (described in Section 4 above). The results of baseline estimation are used to derive a new tagset (detailed in Section 6 below), referred to as T3 in this paper. Then a series of experiments are executed to compare the performance of three tagsets (T1, T2, and T3) on data from two different domains (C1 and C2), as reported in Section 7 below and summarized in Table 4 .

Table 4. Summary of experiments conducted

\begin{tabular}{|c|c|c|c|}
\hline & Experiment & Tagset & Corpus \\
\hline \multirow{2}{*}{0} & \multirow{2}{*}{$\begin{array}{l}\text { Baseline Estimation: } \\
\text { Original tagsets with } \\
\text { respective corpora }\end{array}$} & $\mathrm{T} 1$ & $\mathrm{C} 1$ \\
\hline & & $\mathrm{T} 2$ & $\mathrm{C} 2$ \\
\hline 1 & $\begin{array}{l}\text { Experiment1: For } \\
\text { comparison of results } \\
\text { of T1 and T3 on C1 }\end{array}$ & T3 & C1 \\
\hline \multirow[t]{2}{*}{2} & \multirow{2}{*}{$\begin{array}{c}\text { Experiment2: For } \\
\text { comparison of T1, T2 } \\
\text { and } \mathrm{T} 3 \text { on } \mathrm{C} 2 \\
\end{array}$} & T3 & $\mathrm{C} 2$ \\
\hline & & $\mathrm{T} 1$ & $\mathrm{C} 2$ \\
\hline \multirow{2}{*}{3} & \multirow{2}{*}{$\begin{array}{l}\text { Experiment3: Compar- } \\
\text { ison of T1 and T3 with } \\
\text { no unknowns }\end{array}$} & T3 & $\mathrm{C} 2$ \\
\hline & & $\mathrm{T} 1$ & C2 \\
\hline \multirow[t]{2}{*}{4} & \multirow{2}{*}{$\begin{array}{l}\text { Experiment4: Compar- } \\
\text { ison of T1 and T3 over } \\
\text { complete corpus }\end{array}$} & T3 & $\mathrm{C} 1+\mathrm{C} 2$ \\
\hline & & $\mathrm{T} 1$ & $\mathrm{C} 1+\mathrm{C} 2$ \\
\hline
\end{tabular}

The performance of $\mathrm{T} 1$ on $\mathrm{C} 1$ is already better than $\mathrm{T} 2$ on $\mathrm{C} 2$, so the first comparison for the merged tagset T3 is with $\mathrm{T} 1$ on $\mathrm{C} 1$, which is the basis of the first experiment. Then the performance of better performing tagsets (T1 and T3) are compared on the corpus C2 in the second 
experiment to compare them with T2. One possible reason of relatively better performance could be the difference in application of open classes for unknown words in the test data. Therefore, the third experiment is performed using the same data as in second experiment (i.e. corpus C2) with combined lexicon of training and test data (i.e. no unknown words). Finally, an experiment is conducted with the merged corpus. Following table summarizes these experiments.

\section{Tagset design}

After establishing the baseline, the existing tagsets are reviewed with the following guidelines:

- Focus on the syntactic variation (instead of morphological or semantic motivation) to either collapse existing tags or introduce new ones

- Focus on word level tagging and not try to accommodate phrase level tagging (e.g. to support chunking, compounding or other similar tasks)

- Tag according to the syntactic role instead of having a fixed tag for a string, where possible

- Use PENN Treebank nomenclature to keep the tagset easy to follow and share

Comparison of $\mathrm{T} 1$ and $\mathrm{T} 2$ showed that there are 33 tags in both tagsets which represent same syntactic categories, as shown in Appendix A. The tag I (Intensifier) in T2 labels the words which are marked as ADV in T1. The words annotated as NNC, NNCR and NNCM (under T2) are all labeled as NN under T1. The words tagged as VBL, VBLI, VBI, and VBLI (under $\mathrm{T} 2$ ) are all labeled as VB under T1. Range of distinct tags for demonstratives of $\mathrm{T} 1$ are all mapped to DM in T2 except RD (of T1) which maps to DMRL (of T2).

In order to identify the issues in tagging, a detailed error analysis of existing tagsets is performed. Following tables represent the major tag confusions for tagging C2 with T2 using Tree and TnT taggers.

Table 5. Major misclassifications in C2 with T2 tagset using Tree tagger

\begin{tabular}{|c|c|c|c|c|}
\hline Tag & $\begin{array}{c}\text { Total } \\
\text { tokens }\end{array}$ & Errors & \multicolumn{2}{c|}{$\begin{array}{c}\text { Maximum } \\
\text { misclassification }\end{array}$} \\
\hline VB & 888 & 214 & 183 & VBL \\
\hline VBL & 328 & 168 & 151 & VB \\
\hline VBI & 202 & 47 & 38 & VBLI \\
\hline VBLI & 173 & 52 & 46 & VBI \\
\hline AUXT & 806 & 145 & 121 & VBT \\
\hline
\end{tabular}

Table 6. Major misclassifications in C2 with T2 tagset using TnT-tagger

\begin{tabular}{|c|c|c|c|c|}
\hline Tag & $\begin{array}{c}\text { Total } \\
\text { tokens }\end{array}$ & Error & \multicolumn{2}{c|}{$\begin{array}{c}\text { Maximum } \\
\text { misclassification }\end{array}$} \\
\hline VB & 888 & 240 & 181 & VBL \\
\hline VBL & 328 & 154 & 135 & VB \\
\hline VBI & 202 & 46 & 34 & VBLI \\
\hline VBLI & 173 & 61 & 55 & VBI \\
\hline AUXT & 806 & 136 & 111 & VBT \\
\hline
\end{tabular}

The proposed tagset for Urdu part-ofspeech tagging contains 32 tags. The construction of new tagset (T3) is initiated by adopting $\mathrm{T} 2$ as the baseline, because T2 uses the tagging conventions of PENN Treebank. There are 17 tags in $\mathrm{T} 3$ that are same as in $\mathrm{T} 1$ and $\mathrm{T} 2$. These tags (CC, CD, DM, DMRL, JJ, NN, OD, PM, PRP, PRP\$, PRRF, PRRF\$, PRRL, Q, RB, SM, SYM) are not discussed in detail. The complete tagset along with short description and examples of each tag is given in Appendix B.

RBRP (Adverbial Particle) and CM (Case Marker) are merged to make up a new tag PP (Postposition), so every postposition particle comes under this new tag ignoring semantic context. I (Intensifier) is used to mark the intensification of an adjective, which is a semantic gradation, and syntactically merged with Q (Quantifier). NNCM (Noun after Case Marker), NNC (Noun Continuation), NNCR (Continuing Noun Termination) are merged into NN (Noun) because syntactically they always behave similarly and the difference is motivated by phrase level marking. U (Unit) is also merged with $\mathrm{NN}$ because the difference is semantically motivated.

DATE is not syntactic, and may be either treated as NN (Noun) or CD (Cardinal), depending upon the context. Similarly, R (Reduplication), MOPE (Meaningless Pre-word), and MOPO (Meaningless Post-word) always occur in pair with NN, JJ, or another tag. Thus they are phrasal level tags, and can be replaced by relevant word level tag in context. NNPC (Proper Noun Continuation) tag identifies compounding but syntactically behaves as NNP (Proper Noun), and is not used.

VBL (Light Verb) is used in complex predicates (Butt 1995), but its syntactic similarity with VB (Verb) is a major source of confusion in automatic tagging. It is collapsed with VB (Verb). Similarly, VBLI (Light Verb Infinitive) is merged with VBI (Verb Infinitive). AUXT (Tense Auxiliary) is highly misclassified as VBT (To be Verb) because both occur as last token in a clause or sentence, and both include tense in- 
formation. The word is labeled as VBT only when there is no other verb in the sentence or clause, otherwise these words are tagged as AUXT. The syntactic similarity of both tags is also evident from statistically misclassifying AUXT as VBT. Therefore both are collapsed into single tag VBT (Tense Verb).

In T1, NEG (Negation) is used to mark all the negation words without context, but they mostly occur as adverbs. Therefore, NEG tag is removed. Similarly, SE (Postposition $\Longleftarrow$, "from") is not separated from postpositions and marked accordingly. PRT (Pre-Title) and POT (Post-Title) always occur before or after Proper Noun, respectively. Therefore, they behave as Proper Nouns, hence proposed to be labeled as NNP (Proper Noun).

\section{Experiments}

After designing a new tagset, a series of experiments are conducted to investigate the proposed changes. The rationale of the sequence of experiments has been discussed in Section 5 above, however the reasoning for each experiment is also given below. As T2 tags have much more semantic and phrasal information, and C2 tagged with $\mathrm{T} 2$ shows lower accuracy than $\mathrm{T} 1$ on $\mathrm{C} 1$, therefore further experiments are conducted to compare the performance of $\mathrm{T} 1$ and $\mathrm{T} 3$ only. Comparisons on C2 with T3 may also be drawn.

\subsection{Experiment 1}

As baseline estimation shows that $\mathrm{T} 1$ on $\mathrm{C} 1$ outperforms $\mathrm{T} 2$ on $\mathrm{C} 2$, the first experiment is to compare the performance of $\mathrm{T} 3$ on $\mathrm{C} 1$. In this experiment $\mathrm{C} 1$ is semi-automatically tagged with T3. TnT tagger is then trained and tested. T3 gives $93.44 \%$ accuracy, which is slightly better than the results already obtained for T1 (93.01\%). The results are summarized in Table 7.

Table 7. Accuracies of $\mathrm{T} 3$ and $\mathrm{T} 1$ on $\mathrm{C} 1$

\begin{tabular}{|c|c|c|}
\hline Corpus & Tagset & Accuracy \\
\hline C1 & T3 & $93.44 \%$ \\
\hline C1 & T1 & $93.01 \%$ \\
\hline
\end{tabular}

\subsection{Experiment 2}

Now to test the effect of change in domain of the corpus, the performance $\mathrm{T} 1$ and $\mathrm{T} 3$ on $\mathrm{C} 2$ is compared in this experiment. C2 is manually tagged with $\mathrm{T} 3$, then trained and tested using TnT tagger. The results obtained with $\mathrm{T} 3$ are
91.98\%, which are significantly better than the results already obtained for T2 on C2 (88.13\%).

C2 is also semi-automatically re-tagged with T1. T1 shows better performance (91.31\%) than T2 (88.13\%). However, the accuracy of using T3 (on C2) is still slightly higher. The results are summarized in Table 8.

Table 8. Accuracies of T3 on C1, and accuracies of $\mathrm{T} 3$ and $\mathrm{T} 1$ on $\mathrm{C} 2$

\begin{tabular}{|c|c|c|}
\hline Corpus & Tagset & Accuracy \\
\hline C2 & T3 & $91.98 \%$ \\
\hline C2 & T1 & $91.31 \%$ \\
\hline
\end{tabular}

\subsection{Experiment 3}

Due to the change in open class set there may be a difference of performance on unknown words, therefore in this experiment, all the unknown words of test set are also included in the vocabulary. This experiment again involves T3 and T1 with C2. Combined lexica are built using testing and training parts of the corpus, to eliminate the factor of unknown words. This experiment also shows that $\mathrm{T} 3$ performs better than $\mathrm{T} 1$, as shown in Table 9.

Table 9. Accuracies of T3 and T1 with ALL known words in test data

\begin{tabular}{|c|c|c|}
\hline Corpus & Tagset & Accuracy \\
\hline C2 & T3 & $94.21 \%$ \\
\hline C2 & T1 & $93.47 \%$ \\
\hline
\end{tabular}

\subsection{Experiment 4}

Finally both corpora (C1 and C2) were combined, forming a training set of 203,882 words and a test set of 29,851 words. The lexica are generated only from the training set. Then TnT tagger is trained separately for both $\mathrm{T} 1$ and $\mathrm{T} 3$ tagsets and the accuracies are compared. The results show that $\mathrm{T} 3$ gives better tagging accuracy, as shown in Table 10. Table 10. Accuracies of T3 and T1 using
combined C1 and C2 corpora

\begin{tabular}{|c|c|c|}
\hline Corpus & Tagset & Accuracy \\
\hline $\mathrm{C} 1+\mathrm{C} 2$ & $\mathrm{~T} 3$ & $90.99 \%$ \\
\hline $\mathrm{C} 1+\mathrm{C} 2$ & $\mathrm{~T} 1$ & $90.00 \%$ \\
\hline
\end{tabular}

Partial confusion matrices for both the tagsets are given in Tables 11 and 12. 
The error analysis shows that the accuracy drops for both tagsets when trained on multidomain corpus, which is expected. The highest error count is for the confusion between noun and adjective. There is also confusion between proper and common nouns. T3 also gives significant confusion between personal pronouns and demonstratives, as they represent the same lexical entries.

Table 11. Major misclassifications in merged corpus with T1 using TnT tagger

\begin{tabular}{|c|c|c|c|c|}
\hline Tag & $\begin{array}{c}\text { Total } \\
\text { tokens }\end{array}$ & Error & \multicolumn{2}{|c|}{$\begin{array}{c}\text { Maximum } \\
\text { misclassification }\end{array}$} \\
\hline A & 18 & 5 & 3 & ADJ \\
\hline AD & 18 & 7 & 4 & ADJ \\
\hline ADJ & 2510 & 551 & 371 & NN \\
\hline ADV & 431 & 165 & 59 & ADJ \\
\hline INT & 8 & 6 & 6 & ADV \\
\hline KD & 16 & 9 & 6 & Q \\
\hline KER & 77 & 28 & 19 & P \\
\hline NN & 7642 & 548 & 218 & PN \\
\hline OR & 75 & 24 & 9 & Q \\
\hline PD & 205 & 55 & 12 & PP \\
\hline PN & 2246 & 385 & 264 & NN \\
\hline PP & 239 & 51 & 11 & PD \\
\hline Q & 324 & 119 & 53 & ADJ \\
\hline QW & 24 & 12 & 11 & VB \\
\hline RD & 71 & 62 & 61 & RP \\
\hline RP & 11 & 5 & 2 & NN \\
\hline U & 24 & 8 & 8 & NN \\
\hline
\end{tabular}

Table 12. Major misclassifications in merged corpus with T3 using TnT tagger

\begin{tabular}{|c|c|c|c|c|}
\hline Tag & $\begin{array}{c}\text { Total } \\
\text { tokens }\end{array}$ & Error & \multicolumn{2}{c|}{$\begin{array}{c}\text { Maximum } \\
\text { misclassification }\end{array}$} \\
\hline CVRP & 77 & 24 & 15 & PP \\
\hline DM & 242 & 77 & 58 & PRP \\
\hline DMRL & 71 & 64 & 63 & PRRL \\
\hline INJ & 8 & 6 & 6 & RB \\
\hline JJ & 2510 & 547 & 376 & NN \\
\hline JJRP & 18 & 4 & 4 & JJ \\
\hline NN & 7830 & 589 & 234 & NNP \\
\hline NNP & 2339 & 390 & 267 & NN \\
\hline OD & 75 & 23 & 8 & JJ \\
\hline PRP & 642 & 119 & 33 & DM \\
\hline
\end{tabular}

\section{Discussion and Conclusion}

The current work looks at the existing tagsets of Urdu being used for tagging corpora and analyz- es them from two perspectives. First, the tagsets are analyzed to see their linguistic level differences. Second, they are compared based on their inter-tag confusion after training with two different POS taggers. These analyses are used to derive a more robust tagset.

The results show that collapsing categories which are not syntactically motivated improves the tagging accuracy in general. Specifically, light and regular verbs are merged, because they may come in similar syntactic frames. Reduplicated categories are given the same category tag (instead of a special repetition tag). Units and dates are also not considered separately as the differences have been semantically motivated and they can be categorized with existing tags at syntactic level.

Though, the measuring unit is currently treated as a noun, it could be collapsed as an adjective as well. The difference is sometimes lexical, where kilogram is more adjectival, vs. minute is more nominal in nature in Urdu, though both are units.

NNP (Proper Noun) tag could also have been collapsed with NN (Common Noun), as Urdu does not make clear between them at syntactic level. However, these two tags are kept separate due to their cross-linguistic importance.

One may expect that extending the genre or domain of corpus reduces accuracy of tagging because of increase in the variety in the syntactic patterns and diverse use of lexical items. One may also expect more accuracy with increase in size. The current results show that effect on additional domain (when C1 and C2 are mixed) is more pronounced than the increase in size (from approximately $100 \mathrm{k}$ to $200 \mathrm{k}$ ), reducing accuracy from $94.21 \%$ (T3 with C2) to $90.99 \%$ (T3 with $\mathrm{C} 1+\mathrm{C} 2)$. The increase in accuracy for T3 vs. T1 may be caused by reduced size of T3. However, the proposed reduction does not compromise the syntactic word level information, as the collapsed categories are where they were either semantically motivated or motivated due to phrasal level tags.

The work has been motivated to consolidate the existing Urdu corpora annotated with different tagsets. This consolidation will help build more robust computational models for Urdu.

\section{References}

Brants, T. 2000. TnT - A statistical part-of-speech tagger. Proceedings of the Sixth Applied Natural Language Processing Conference ANLP-2000 Seattle, WA, USA. 
Butt, M. 1995. The structure of complex predicates in Urdu. CSLI, USA. ISBN: 1881526585.

Haq, A,. 1987. اردو صرف و نحو Amjuman-e-Taraqqi Urdu.

Hardie, A. 2003. Developing a tag-set for automated part-of-speech tagging in Urdu. Archer, D, Rayson, P, Wilson, A, and McEnery, T (eds.) Proceedings of the Corpus Linguistics 2003 conference. UCREL Technical Papers Volume 16. Department of Linguistics, Lancaster University, UK.

Hussain, S. 2008. Resources for Urdu Language Processing. The Proceedings of the 6th Workshop on Asian Language Resources, IJCNLP'08, IIIT Hyderabad, India.

Ijaz, M. and Hussain, S. 2007. Corpus Based Urdu Lexicon Development. The Proceedings of Conference on Language Technology (CLT07), University of Peshawar, Pakistan.

Javed, I. 1981. نئى اردو قوائد Taraqqi Urdu Bureau, New Delhi, India.

Platts, J. 1909. A grammar of the Hindustani or Urdu language. Reprinted by Sang-e-Meel Publishers, Lahore, Pakistan.

Sajjad, H. 2007. Statistical Part of Speech Tagger for Urdu. Unpublished MS Thesis, National University of Computer and Emerging Sciences, Lahore, Pakistan.

Sajjad, H. and Schmid, H. 2009. Tagging Urdu Text with Parts Of Speech: A Tagger Comparison. $12^{\text {th }}$ conference of the European chapter of the association for computational Linguistics

Santorini, B. 1990. Part_of_Speech Tagging Guidelines for the Penn Treebank Project $\left(3^{\text {rd }}\right.$ printing, $2^{\text {nd }}$ revision). Accessed from ftp://ftp.cis.upenn.edu/pub/treebank/doc/tagguide.ps.gz on 3rd May, 2009.

Schmid, H. 1994. Probabilistic part-of-speech tagging using decision trees. Institut für Maschinelle Sprachverarbeitung, Universität Stuttgart, Germany.

Schmidt, R. 1999. Urdu: an essential grammar. Routledge, London, UK.

McEnery, A., Baker, J. Gaizauskas, R. and Cunningham, H. 2000. EMILLE: towards a corpus of South Asian languages, British Computing Society Machine Translation Specialist Group, London, UK.
Appendix A: Mappings of tags between Tagsets $\mathrm{T} 1$ and $\mathrm{T} 2$.

\begin{tabular}{|c|c|c|}
\hline & Tagset T1 & Tagset T2 \\
\hline 1. & A & JJRP \\
\hline 2. & AA & AUXA \\
\hline 3. & ADJ & $\mathrm{JJ}$ \\
\hline 4. & $\mathrm{ADV}$ & $\mathrm{RB}$ \\
\hline 5. & CA & CD \\
\hline 6. & $\mathrm{CC}$ & $\mathrm{CC}$ \\
\hline 7. & DATE & DATE \\
\hline 8. & EXP & SYM \\
\hline 9. & FR & FR \\
\hline 10. & G & PRP\$ \\
\hline 11. & GR & PRRFP\$ \\
\hline 12. & $\mathrm{I}$ & ITRP \\
\hline 13. & INT & INJ \\
\hline 14. & KER & KER \\
\hline 15. & MUL & MUL \\
\hline 16. & $\mathrm{NN}$ & $\mathrm{NN}$ \\
\hline 17. & OR & OD \\
\hline 18. & $\mathrm{P}$ & $\mathrm{CM}$ \\
\hline 19. & PD & DM \\
\hline 20. & PM & PM \\
\hline 21. & $\mathrm{PN}$ & NNP \\
\hline 22. & PP & PR \\
\hline 23. & $\mathrm{Q}$ & $\mathrm{Q}$ \\
\hline 24. & QW & QW \\
\hline 25. & $\mathrm{RD}$ & DMRL \\
\hline 26. & REP & PRRL \\
\hline 27. & $\mathrm{RP}$ & PRRF \\
\hline 28. & SC & SC \\
\hline 29. & SE & RBRP \\
\hline 30. & SM & $\mathrm{SM}$ \\
\hline 31. & TA & AUXT \\
\hline 32. & $\mathrm{U}$ & $\mathrm{U}$ \\
\hline 33. & WALA & WALA \\
\hline
\end{tabular}


Appendix B: New Tagset T3.

\begin{tabular}{|c|c|c|c|c|}
\hline & Tag & Meaning & Example & \\
\hline 1. & AUX & Auxiliary & منتقل كر سكت بو & May \\
\hline 2. & CC & Coordinate Conjunction & ملازمين يا حكومتى عهيه دارون ك ذ ذريع & Or \\
\hline 3. & CD & Cardinal & ايك موجوده اداكار كو & One \\
\hline 4. & CVRP & $\begin{array}{l}\text { Conjunctive Verb Par- } \\
\text { ticle }\end{array}$ & فرانسيسى قلع بيج كر بهى فندُز برُهاخ ير راضى نـ & After \\
\hline 5. & $\mathrm{DM}$ & Demonstrative & يهيل ايسع واقعات نر بوخ لخ برابر ته & Like this \\
\hline 6. & DMRL & Demonstrative Relative & بين وهاعتى اداره سـ جو وه 23 سال تك جلا حِح & That \\
\hline 7. & FR & Fraction & آدهـ گهنث ميس & Half \\
\hline 8. & INJ & Interjection & واه! كيا بات بـ & Hurrah \\
\hline 9. & ITRP & Intensive Particle & نه گهرا تها نـ بى باقى ربن والا & Too \\
\hline 10. & JJ & Adjective & بلند تر لاكتول ع ساته & Taller \\
\hline 11. & JJRP & Adjective Particle & بابر ريخ كى بهت سى وجوبات كو سوج سكت بين & As \\
\hline 12. & MRP & Multiplicative Particle & دכنى رقم & Double \\
\hline 13. & NN & Noun & سال ك آ غاز مي افوابون ير & Year \\
\hline 14. & NNP & Proper Noun & رابرث خ كها & Robert \\
\hline 15. & OD & Ordinal & يهيلا ريثائرمنت منصوبر & First \\
\hline 16. & PM & Phrase Marker & & , \\
\hline 17. & $\mathrm{PP}$ & Postposition & بوردُ ركنيت نو تك برُهاخ بوحُ & To \\
\hline 18. & PRP & Pronoun Personal & وَ طريق كار كو استعمال ح ابل بونا يسند كرين & They \\
\hline 19. & PRP\$ & $\begin{array}{l}\text { Pronoun Personal } \\
\text { Possessive }\end{array}$ & ميرى تيز كَيند اجهى بـ & My \\
\hline 20. & PRRF & Pronoun Reflexive & كمينى خ ايخ آَّ كو بخوبى & Oneself \\
\hline 21. & PRRF\$ & $\begin{array}{l}\text { Pronoun Reflexive } \\
\text { Possessive }\end{array}$ & اين اجتماعى دفاتر & Own \\
\hline 22. & PRRL & Pronoun Relative & بين وهاعتى اداره سِ جو وه 23 سال تك جلا حِح & That \\
\hline 23. & $\mathrm{Q}$ & Quantitative & جند لوگ & Some \\
\hline 24. & QW & Question Word & ايك مصنف كيون يقين كر> B B & Why \\
\hline 25. & $\mathrm{RB}$ & Adverb & بميشـ بيحى گثئى & Always \\
\hline 26. & SC & Subordinate Conjunction & كتنا ركه گى كيونك كجه نوكريان & Because \\
\hline 27. & SM & Sentence Marker & $\uparrow$ & $?$ \\
\hline 28. & SYM & any Symbol & $\$$ & $\$$ \\
\hline 29. & VB & Verb & مهنغ كرِّا حابِ ته & Wanted \\
\hline 30. & VBI & Verb Infinitive form & اسع لحاخ غ لي & To go \\
\hline 31. & VBT & Verb Tense & تصور قابل عمل بح & Is \\
\hline 32. & WALA & $\begin{array}{l}\text { Association Marking } \\
\text { Morpheme }\end{array}$ & ركارى كراخ والاح & $\begin{array}{l}\text { Associated } \\
\text { Bearing }\end{array}$ \\
\hline
\end{tabular}

